\title{
Mutations in the p53 gene at codon 249 are rare in squamous cell carcinoma of the head and neck
}

\author{
J. K. FIELD ${ }^{1}$, A. MALLIRI ${ }^{1,2}$, A. J. JONES ${ }^{3}$ and D. A. SPANDIDOS ${ }^{2,4}$ \\ ${ }^{1}$ Department of Clinical Dental Sciences, School of Dentistry, University of Liverpool, PO Box 147, Liverpool L69 3BX, UK; \\ ${ }^{2}$ Institute of Biological Research and Biotechnology, National Hellenic Research Foundation, 48 Vas Constantinou Avenue, \\ 11635 Athens, Greece; ${ }^{3}$ Department of Otorhinolaryngology, University of Liverpool, PO Box 147, Liverpool L69 3BX, UK; \\ ${ }^{4}$ Medical School, University of Crete, Heraklion, Greece \\ Contributed by D.A. Spandidos May 15, 1992
}

\begin{abstract}
Mutations in the p53 tumour suppressor gene are common in a wide range of human malignancies. In particular $\mathrm{G} \rightarrow \mathrm{T}$ transversions in the p53 gene occur at a high frequency in lung cancer tumours and as the same mutagens maybe responsible for p53 mutations in head and neck squamous cell carcinomas, a preliminary investigation was carried out to establish if this may be the case. Codon 249 of the p53 gene has been found to be a hot spot of $G \rightarrow T$ transversions in hepatocellular carcinomas, thus it was decided to initially investigate this site using specific primers and restricting the PCR product with the HaeIII restriction endonuclease. Fifty seven squamous cell carcinomas of the head and neck were investigated using this technique and no mutations were found at codon 249 in the p53 gene. In this study twenty six of the specimens were also examined immunohistochemically using a number of antibodies to p53 (PAb 421, PAb 1801 and CM-1), and 19 were found to have positive staining. Moreover as positive p53 staining is considered to be synonymous with p53 mutations, over two thirds of our earlier immunohistochemical study indicated p53 mutations in head and neck tumours. The technique used in this paper has the advantage of scanning a large number of tumours for mutations at suspect sites and maybe of use in the future if specific mutational hot spots are found in the p53 gene in head and neck cancers. In the meantime p53 mutations in these tumours are been investigated by conventional sequencing techniques.
\end{abstract}

\section{Introduction}

Aberrant p53 expression is now considered to be one of the commonest genetic events in a wide range of human cancers (1). The development of a number of antibodies to the p53 gene

Correspondence to: Dr J.K. Field, Department of Clinical Dental Sciences, School of Dentistry, University of Liverpool, PO Box 147, Liverpool L69 3BX, UK

Key words: p53 onco-suppressor gene, squamous cell carcinoma, head and neck tumors product has enabled many groups to utilise immunohistochemical methods to estimate the frequency of p53 over-expression in human tumours. Over-expression of the p53 gene has been considered to be synomous with p53 mutations, as mutations in this gene generally increase the stability of the p53 protein (2). However it is now recognised that certain tumours may not accumulate p53 protein but may still be mutant in the p53 gene, due to inactivated expression of both alleles or point mutations that do not stabilise the protein.(3-6).

P53 mutations were recently reviewed by Hollstein et al (1) and they demonstrated that $98 \%$ of the 280 base substitutions analysed fell within 600 base pairs of the p53 gene - from codons 110 to 307 , encompassing exons 5 to 8 inclusive. In particular these authors pointed out that the spectra of p53 mutations differed depending on the tumour type and that analysis of the specific nucleotide substitutions may provide clues to the etiology of these tumours.

P53 expression has been analysed in squamous cell carcinomas of the head and neck using a number of antibodies (7). Overexpression of p53 was found in 49/73 (67\%) (8) and $16 / 34$ (34\%) (9) of these tumours. Apart from two head and neck cell lines there is no published information on the location of these p53 mutations. Overexpression of the p53 gene has not been shown to correlate with any of the clinicopathological parameters in head and neck cancer (8) however it has been shown to correlate with a history of heavy smoking and heavy drinking (10).

In lung tumours $\mathrm{G} \rightarrow \mathrm{T}$ transversions have been found in $56 \%$ of cases (3) and these mutations were not found to be clustered at any one particular site within the p53 gene. In view of the epidemiological evidence for the etiology of both lung cancer and head and neck cancer, it is feasible that a similar mutagen maybe acting at both of these cancer sites and a high proportion of $\mathrm{G} \rightarrow \mathrm{T}$ transversions in the p53 gene may also be found in head and neck cancer. We decided to study one specific site in the p53 gene that has been previously shown to have a high frequency of $G \rightarrow T$ transversions. A mutational hotspot has been found in hepatocellular carcinomas in the Qidong region in China (11) and in Southern Africa (12), where 12/26 patients had $G \rightarrow T$ transversions at codon 249 in the p53 gene. Also mutations in 


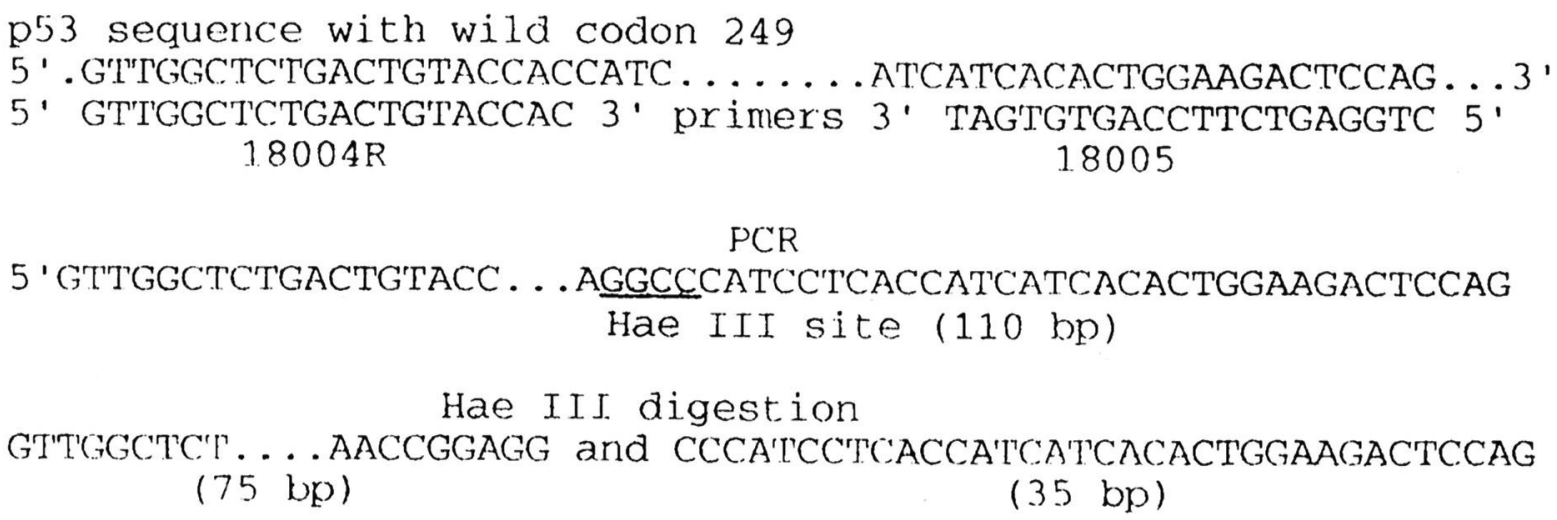

Figure 1. Primers used to amplify the p53 gene in the region of codon 249. A natural Hae III site exists in the wild type 249 codon.

A
1234

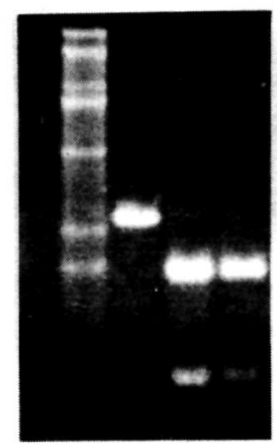

B

123

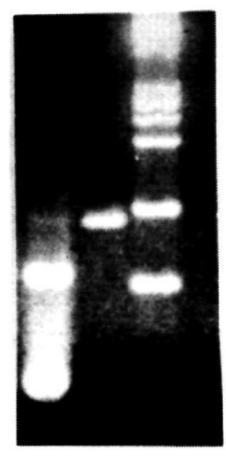

Figure 2. R.F.L.P. analysis of head and neck squamous cell carcinoma specimens. A. Lane (1) pUC HaeIII molecular weight marker, (2) amplified PCR product, patient number 271 (3-4) digested PCR products from patient numbers 271 and 74. B. (1) digested PCR product from patient number 274, (2) amplified PCR product, patient number 277, (3) $\varphi \times 174$ HaeIII molecular weight marker.

single samples of cancer of the lung, breast and oesophagus have been reported at this site (1).

We have used a new and sensitive technique for the detection of p53 mutations at codon 249, based on the existance of a HaeIII restriction site at the wild type for codon 249, PCR product.

\section{Materials and methods}

Tumour specimens. Fifty seven squamous cell carcinomas of the oral cavity, larynx and pharynx were examined for a p53 mutation at codon 249 . Fortyone specimens of patients were snap frozen at the time of surgery. Also a number of tumour specimens were analysed from 16 patients at different stages of chemotherapy treatment. The latter specimens were all paraffin embedded. Clinical and pathological parameters and follow up data were available for all of the patients analysed.

DNA specimens. DNA was extracted from frozen tumour and normal tissue specimens by the methods previously described
(14) Specimens that were fixed by formalin in paraffin embedded sections were extracted by boiling in a lysis buffer.

Oligonucleotide primers and probes. The oligodeoxynucleotides were synthesised by the solid phase triester method.

Polymerase chain reactions. In vitro enzymatic DNA amplification (PCR) was performed on an automated thermal cycler using the methods described by Saiki et al (15). Thirty five reaction cycles were used, each of $30 \mathrm{sec}$. at $95^{\circ} \mathrm{C}, 30 \mathrm{sec}$. at $58^{\circ} \mathrm{C}$ and $50 \mathrm{sec}$. at $72^{\circ} \mathrm{C}$. Primers were designed to be used for the PCR amplification of the p53 region surrounding codon 249. The PCR was performed with the two primers and a HaeIII recognition site existed if p53 codon 249 was wild type (Fig. 1). However the HaeIII recognition site would not be formed if there was a mutation at codon 249. This approach is similar to that described by Haliassos et al (13). An aliquot of the PCR reaction product was first run on a $2 \%$ agarose gel for the presence of the amplified fragment (110bp). In the case of a wild type sequence at codon 249 , the PCR product gave two fragments (75bp) and (35bp) when digested with HaeIII (Fig. 1).

Antibodies. The rabbit antiserum CM-1 has been raised against full length p53 expressed in E.coli using a modified T7 based expression vector (16) such that the first methionine of p53 was the initiation codon. This resulted in an expression vector that encodes a full length p53 protein that is not fused to any of other protein sequences (17). The CM-1 antibody was used at a concentration of 1 in 50 (IRL). The avidin-biotin $(A B C)$ technique was used to stain the paraffin embedded sections with the CM-1 antibody (18). Control slides omitting the first antibody were used as negative controls as well as using an irrelevant mouse monoclonal antibody. Positive controls included the MRSV3.1 human breast cell line immortalised with a retroviral vector carrying the $\mathrm{SV}-40$ large $\mathrm{T}$ antigen gene (obtained from Dr Joyce Taylor-Papadimitriou ICRF). PAb 421 and PAb 1801 (Oncogene Science) antibodies were also used to determine p53 expression on a selection of these tumours as previously described in Field et al (8). 

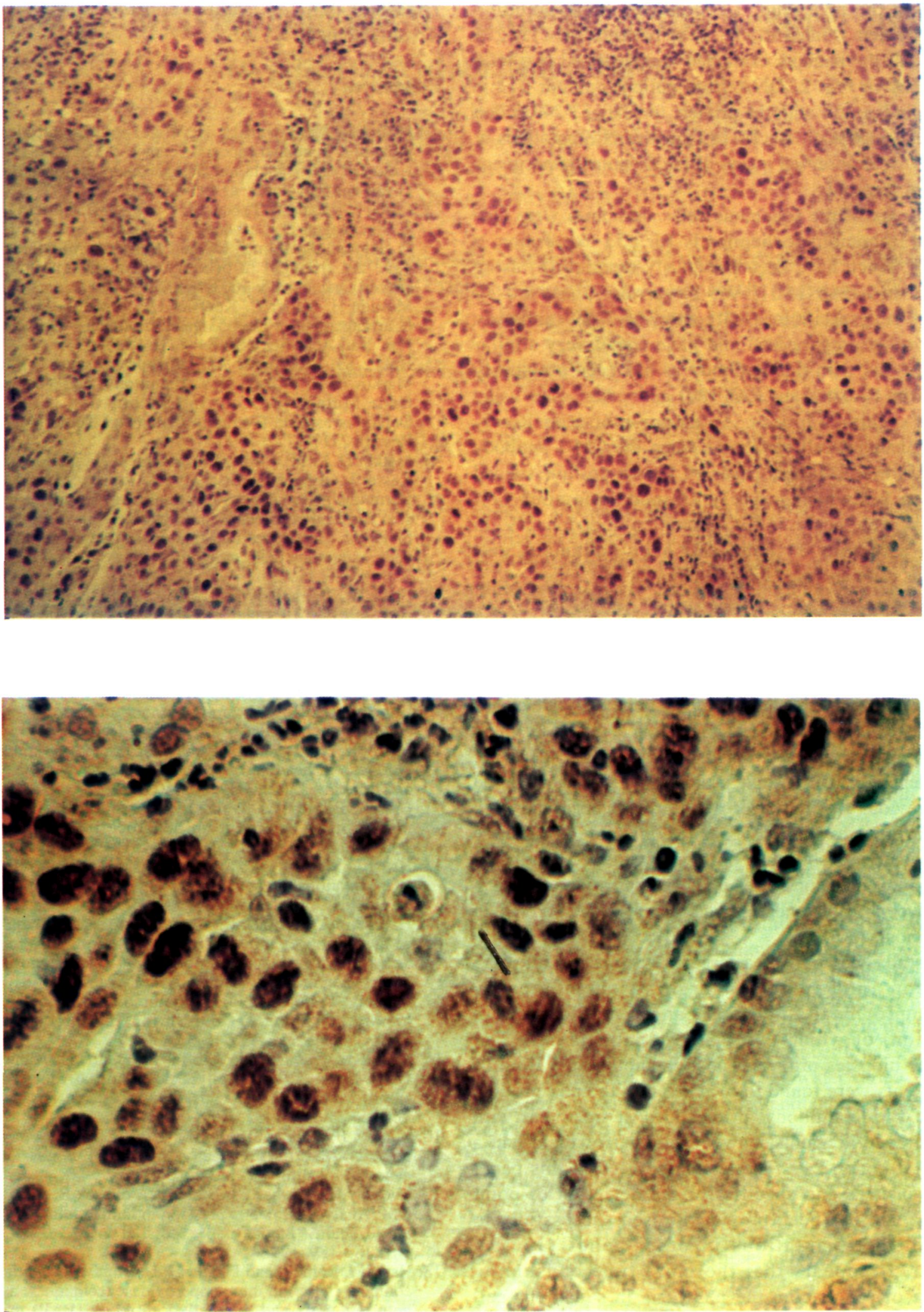

Figure 3. A. Infiltrating squamous cell carcinoma of the head and neck (Patient number 280) stained with p53 CM-1 antibody showing all of the neoplastic cells with intense nuclear staining $(x 250$ ). B. Higher magnification of the previous Figure 3.A showing neoplastic cells with intensely stained nuclei. The normal cells of the adjacent are unstained $(\mathrm{x} 400)$ 


\section{Results}

Fifty seven squamous cell carcinomas were examined for a mutation in the p53 gene at codon 249. Representative tumours are demostrated in Fig. 2. of patients 74, 271, 274 and 277. All the patients examined demonstrated two wild type alleles. In Fig. 2, DNA from patient number 271 is amplified in lane A2 with the primers for the p53 249 codon site and digested with HaeIII in lane A3. No mutations at codon 249 were observed in any of the 57 tumour specimens analysed in this study.

Twenty six of the squamous cell carcinomas were also examined immunohistochemically for p53 expression, a number of which have been previously reported (8) using PAb 421 and PAb 1801. We have now analysed 40 squamous cell carcinomas with the CM-1 p53 antibody (Field et al in preparation) and have found very similar staining results with this antibody as has been previously reported with PAb 420 and PAb 1801 antibodies, when using the same specimen blocks. An example of a positively staining squamous cell carcinoma using the CM-1 antibody is shown in Fig. 3. In this paper 19 known positive stained and seven known negatively stained squamous cell carcinomas were analysed for a mutation at codon 249 . In addition a further 31 head and neck squamous cell carcinomas were analysed for a mutation at 249 .

\section{Discussion}

Point mutations in the p53 gene at codon 249 in head and neck squamous cell carcinomas would appear to be very rare events as we have found no evidence of a mutation at this codon in 57 tumour specimens analysed. Within this group of patients we have evidence for $\mathrm{p} 53$ positive staining in 19 tumours. Based on our previous findings over two thirds of head and neck tumours overexpress the p53 gene (8), therefore 38 of these tumours would probably stain positively with a p53 antibody. In addition it is now considered that overexpression of the p53 gene product probably underestimates the p53 mutation rate in human tumours (3-6).

This study was part of a larger investigation into p53 expression in patients undergoing chemotherapy treatment for head and neck cancer (Field et al in preparation) of which two of these patients have had surgery or biopsies prior and post chemotherapy. Both of these patients were found to over-express the p53 product using the CM-1 antibody, prior and post treatment with chemotherapeutic agents, however neither of them had a mutation at codon 249. The technique used in this paper is both sensitive and specific for the detection of point mutations and has been previously used successfully to detect specific mutations in other genes $(13,19)$. However, it appears that the more time consuming technique of sequencing the p53 gene in squamous cell carcinomas of the head and neck is required to determine the particular mutations in these tumours and this is presently been undertaken in our laboratory. In time the sequencing data on these tumours may provide clues as to whether specific p53 mutations are associated with a particular carcinogen in head and neck cancers (20).

\section{Acknowledgements}

This research was supported by the British-American Tobacco Company Limited and the North West Cancer Research Fund, UK.

\section{References}

1. Hollstein M, Sidransky D, Vogelstein B and Harris C: p53 mutations in human cancers. Science 253: 49-53, 1991.

2. Lane DP and Benchimol S: p53 oncogene or anti- oncogene? Genes and Development 4: 1-8, 1990.

3. Chiba I, Takahashi T, Nau M, D'Amico D, Curiel D, Mitsudomi T, Buchhagen D, Carbone D, Piantadosi S, Koga H, Reissman P, Slamon D, Holmes EC and Minna J: Mutations in the p53 gene are frequent in primary resected non-small cell lung cancer. Oncogene 5: 1603-1610, 1990.

4. Masuda H, Miller C, Koeffler HP, Battifora $\mathrm{H}$ and Cline MJ: Rearrangement of the p53 gene in human osteogenic sarcomas. Proc Natl Acad Sci USA 84: 7716-7719, 1987.

5. Baker SJ, Preisinger AC, Milburn Jessup J, Paraskeva C, Markowitz S, Willson JKV, Hamilton S and Vogelstein B: p53 Gene Mutations Occur in Combination with 17p Allelic Deletions as Late Events in Colorectal Tumorigenesis. Cancer Res 50: 7717-7722, 1990

6. Malkin D, Li FP, Strong LC, Fraumeni JF, Nelson CE, Kim DH, Kassel J, Gryka MA, Bischoff FZ, Tainsky MA and Friend SH: Germ line p53 mutations in a familial syndrome of breast cancer, sarcomas and other neoplasms. Science 250: 1233-1238, 1990.

7. Field JK: Oncogenes and tumour suppresor genes in head and neck squamous cell carcinomas. Oral Oncology Eur J Cancer 28B: 67-76, 1992.

8. Field JK, Spandidos DA, Malliri A, Yiagnisis M, Gosney JR and Stell PM: Elevated p53 expression correlates with a history of heavy smoking in squamous cell carcinoma of the head and neck. Br J Cancer 64: 573-577, 1991.

9. Gusterson BA, Anbazhagan R, Warren W, Midgely C, Lane DP, O'Hare M, Stamps A, Carter R and Jayatilake H: Expression of p53 in premalignant and malignant squamous epithelium. Oncogene 6: 1785-1789, 1991.

10. Field JK, Spandidos DA and Stell PM: Overexpression of the p53 gene in head and neck cancer, linked with heavy smoking and drinking. Lancet 339: 502-503, 1992.

11. Bressac B, Kew M, Wands J and Ozturk M: Selective G to T mutations of p53 gene in hepatocellular carcinoma from southern Africa. Nature 350: 429-431, 1991

12. Hsu IC, Metcalf RA, Sun T, Welsh JA, Wang NJ and Harris CC: Mutational hotspot in the p53 gene in human hepatocellular carcinomas. Nature 350: 427-428, 1991.

13. Haliassos A, Chomel JC, Grandjouan S, Kaplan JC and Kitzis A: Detection of minority point mutations by modified PCR technique: a new approach for a sensitive diagnosis of tumour progression markers. Nucleic Acid Res 17: 8093-8100, 1989.

14. Maniatis T, Fritsch EF and Sambrook J: Molecular Cloning. A Laboratory Manual. Cold Spring Harbor Laboratory Cold Spring New York, 1982.

15. Saiki RH, Gelfand DH, Stoffel S, Scharf SJ. Higuchi R, Horn GT, Mullis KB, Erlich HA: Primer directed enzymatic amplification of DNA with a thermo-stable DNA polymerase. Science 239: 487-491, 1988.

16. Studier FW and Moffatt BA: Use of bacteriophage T7 RNA polymerase to direct selective high-level expression of cloned genes J Mol Biol 189: 113-130, 1986.

17. Midgley CA, Fisher CJ, Bartek J, Vojtesek B, Lane DP, Barnes DM: Analysis of p53 expression in human tumours: an antibody raised against human p53 expressed in E coli. J Cell Science 101: 183-189, 1992.

18. Hsu SM, Raine $L$ and Fanger $H$ : Use of avidin-biotin peroxidase complex $(\mathrm{ABC})$ in immunoperoxidase techniques: a comparison between $\mathrm{ABC}$ and unlabelled antibody (PAP) procedures. J Histochem Cytochem 29: 577, 1981.

19. Skalkeas GRD, Spandidos DA, Kostakis A, Balafouta-Tseleni $\mathrm{S}$, Choremi E, Iliopoulos D and Haliassos A: K-ras oncogene mutations in neoplasias of kidney transplanted patients: Preliminary results with a new technique. Anticancer Res 11: 2091-2094, 1991.

20. Harris CC: Chemical and physical carcinogenesis: advances and perspectives for the 1990's. Cancer Res 51: 5023-5044, 1991. 